\title{
OPTIC NERVE TUMOUR TREATED BY KRONLEIN'S LATERAL ORBITOTOMY*
}

\author{
BY \\ N. S. JAIN \\ Department of Ophthalmology, Irwin Hospital, New Delhi, India
}

\section{Case Report}

A boy aged 12 complained of pain in the left eye on July 27, 1955, when the visual acuity in each eye was reported to be 6/6. On August 26, 1955, the visual acuity in the right eye was still $6 / 6$, but that in the left eye was reduced to $6 / 12$, and there was noticeable left-sided exophthalmos. On January 4, 1956, the left eye was blind and the proptosis had markedly increased. $X$ rays showed the left optic foramen to be enlarged and a diagnosis of glioma of the optic nerve was made in Calcutta.

The boy was examined by me for the first time on September 26, 1956, when the findings and diagnosis were confirmed. There was a marked proptosis on the left side, the eyeball being displaced downwards and inwards (Fig. 1). The ocular movements were restricted upwards and outwards. The left fundus showed optic atrophy, the papilla was swollen, and the vessels were engorged and tortuous. On and around the disc a few abnormal vessels were seen.

Operation.-Kronlein's lateral orbitotomy was performed by me on October 8, 1956. The presence of an optic nerve tumour was confirmed and this was excised in toto. Only one complication was encountered; the bony fragment was fractured while being removed.

The post-operative recovery, except for an irregularly febrile course for the first 4 days, was uneventful.

Result.-Fundus examination 4 days after the operation showed a completely ischaemic retina. On the tenth day adduction was normal, abduction was absent, and elevation and depression of the globe were restricted. At the time of discharge on October 29, 1956, there was a slight ptosis of the left upper lid and a convergent squint of the lef eye. The proptosis had decreased by $10 \mathrm{~mm}$. (Fig. 2).

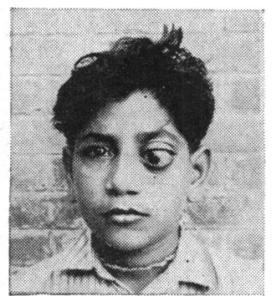

FIG. 1.-Appearance of the patient before Kronlein's operation.

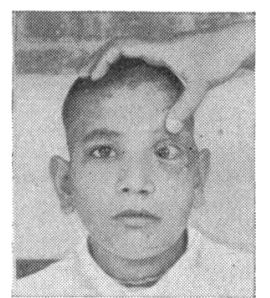

Fig. 2.-Appearance at the time of discharge 3 weeks later. 
Histopathological Examination.-Macroscopically the excised mass (Fig. 3) showed a totally neoplastic optic nerve with intact sheaths and necrosis at its posterior end, its diameter being $0.8 \mathrm{~mm}$.

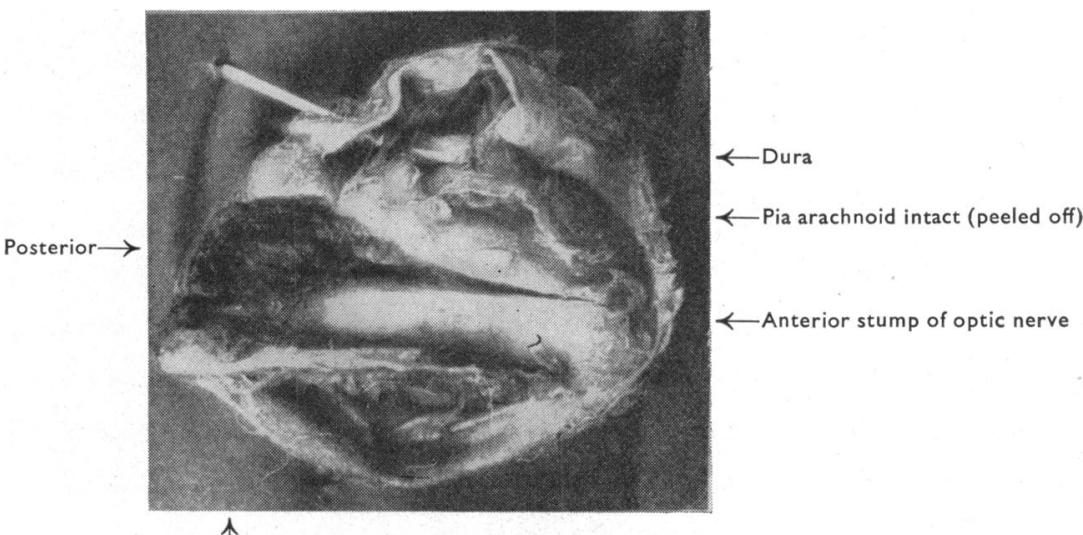

Necrosis at posterior end

FIG. 3.-Excised mass. $\times 3$.

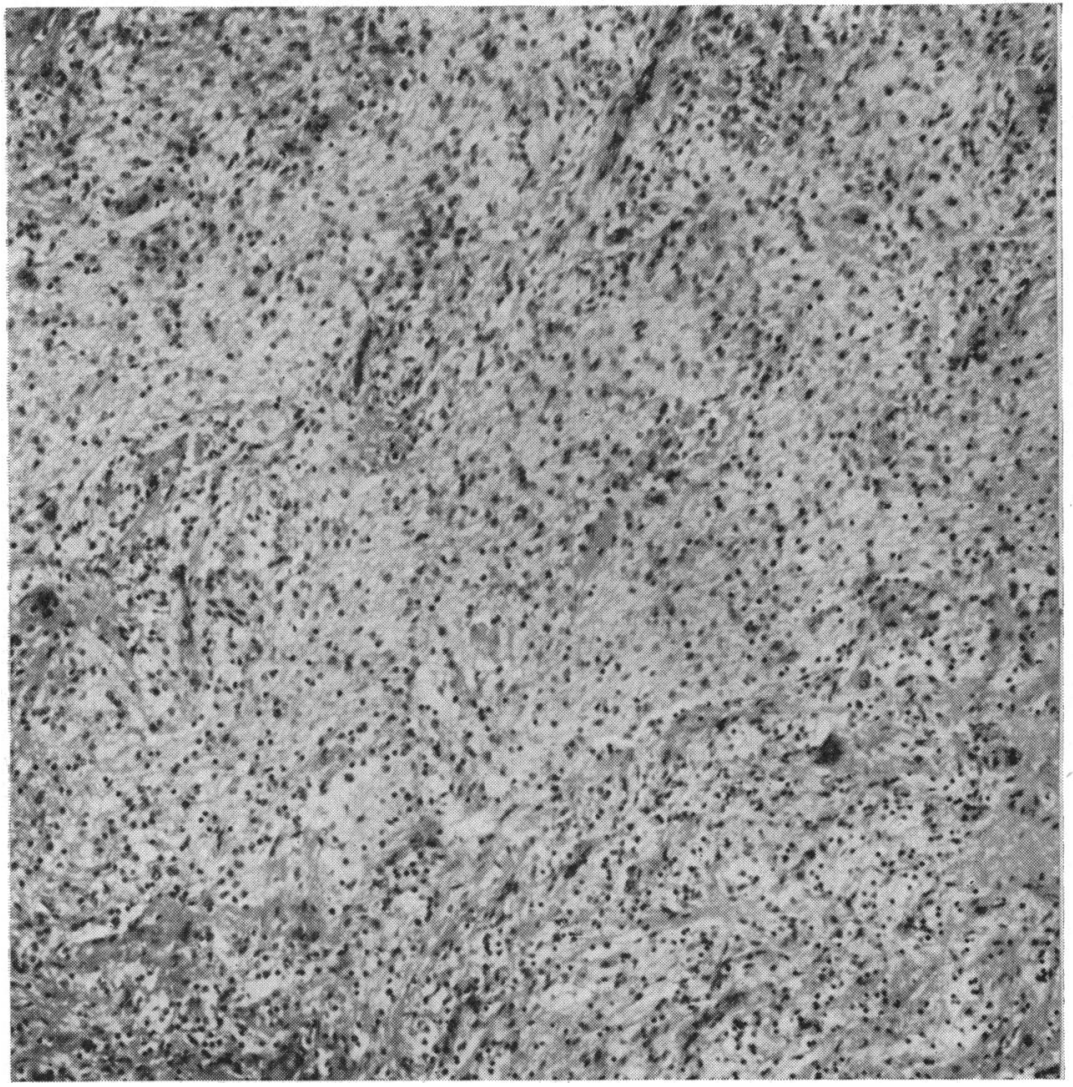

\section{ำ}

ध

高

ㅇํำ

ญ

옥

亮

흠

응

을.

ᄋ̊ำ

§

욱

근

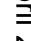

N

N

స్ట

एँ

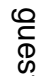

FIG. 4.-Transverse section of neoplasm (by courtesy of the Institute of Ophthalmology, London). 
A section was submitted for microscopical examination to Dr. N. Ashton of the Institute of Ophthalmology, London, who made the following report:

The section submitted for examination is stained with haematoxylin and eosin, and shows a portion of optic nerve in which the septa are distorted and widely separated by proliferating masses of glial cells with pale round or oval nuclei and well-marked cytoplasmic vacuoles. They lie in a dense stroma of delicate fibres, and in some areas surround irregular spaces containing hyaline eosinophilic transudate. The histological picture is typical of glioma of the optic nerve (Fig. 4).

Follow up (June 17, 1957).-The result was excellent in the primary position; there is no ptosis (Fig. 5), normal adduction (Fig. 6), and normal depression (Fig. 7). Defective elevation (Fig. 8) and restricted abduction (Fig. 9) are the only delayed sequelæ of this operation.

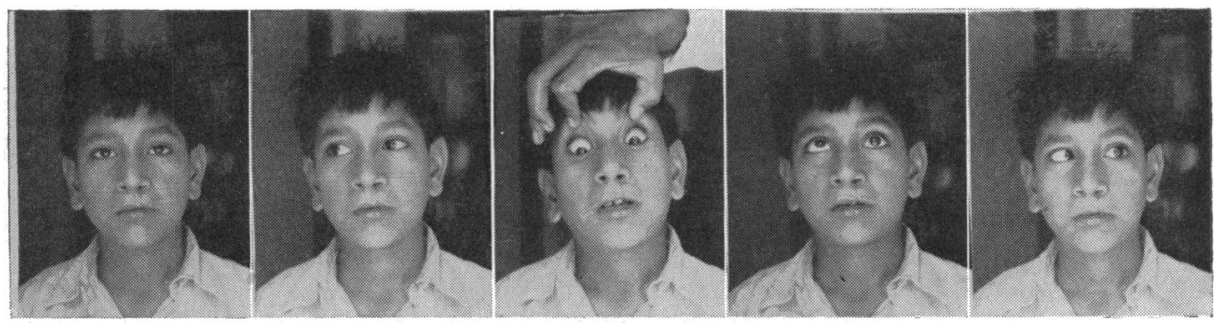

Fig. 5.-Primary Fig. 6.-Normal Fig. 7.-Normal Fig. 8.-Defective Fig. 9.-Restricted position adduction depression elevation of left eye eye

The left eye is slightly enophthalmic, and the size of each pupil, despite total blindness on the left side, is $3 \mathrm{~mm}$. The left pupil does not react at all.

\section{Summary}

A case is reported of oligodendroglioma of the optic nerve, successfully treated by Kronlein's operation.

My thanks are due to Dr. Norman Ashton, Director of Pathology, Institute of Ophthalmology, London, for histopathological report and the photomicrograph. 